\title{
Identification Transgenic DNA of Transformed Arabidopsis Using PCR and Southern Blot
}

\author{
Al-Baraa Akram, Glen McCann, Triaziana Sgamma \\ Department of Pharmaceutical Biotechnology, De Montfort University, Leicester, UK \\ Email: albraaakram94@gmail.com
}

How to cite this paper: Akram, A.-B., McCann, G. and Sgamma, T. (2022) Identification Transgenic DNA of Transformed Arabidopsis Using PCR and Southern Blot. Advances in Bioscience and Biotechnology, 13, 134-144.

https://doi.org/10.4236/abb.2022.133006

Received: December 28, 2021

Accepted: March 1, 2022

Published: March 4, 2022

Copyright () 2022 by author(s) and Scientific Research Publishing Inc. This work is licensed under the Creative Commons Attribution International License (CC BY 4.0).

http://creativecommons.org/licenses/by/4.0/

\begin{abstract}
For identification of transgenic DNA of Arabidopsis plant material, the followed methods are transformation and growing of seeds after bleaching them for sterilization should be performed then using polymerase chain reaction (PCR) for amplification the gene before making gel electrophoresis to be ready for southern blot analysis, this method is possible because the length of the given primers, there are slightly modifications in the methods as ligating PCR technique developed for amplification of the unknown DNA after extracting it to determine its transgenicity. The methods were specific and reproducible for many different plants from transgenic and non-transgenic cell lines. Furthermore, the number of products of PCR result can be considered as a good estimation of transgenic DNA, during comparison to southern blot analysis, the results obtained by the PCR give information about DNA of Arabidopsis, applications of the approach to Arabidopsis plants after transformation with an Agrobacterium-mediated transformation will be described.
\end{abstract}

\section{Keywords}

Arabidopsis, Southern Blot, Polymerase Chain Reaction, Agrobacterium, Primeres

\section{Introduction}

Arabidopsis is a plant from the family Cruciferae or Brassicaceae, it is one of the flowering plants related to white and black mustard this genus of plant is ideal for studying plant biology as the first complete sequence studied was the seeds of this plant for getting the complete genome [1].

Agrobacterium is a gram-negative bacteria used for gene transfer as it has the ability to transfer DNA between other plants, fungi and itself so it is a crucial tool for plant genetic engineering for improvement of the plant by transforma- 
tion [2], the gene is recombined with the plant e.g. Arabidopsis species and then cloned using plant vector transformation in the presence of a suitable marker [3] which is antibiotic resistance for best selection of successfully transformed plant which is grown in the media with antibiotic after transformation [4] [5].

Methods and analysis procedures used for getting transgenic Arabidopsis plants by transformations with Agrobacterium results in generation of various number of DNA copies at different locations on the plant chromosomes, these copies can affect the stability and the level of the expression of the gene so the identification of the transgenes should be conducted for familiar analysis of transgenic expression levels which should be unique procedures [6].

In this report, seeds (T1 generation) will be used of N70756 strains obtained from Arabidopsis plants transformed with an Agrobacterium-mediated transformation, after extracting the genomic DNA from plant PCR based method will be used and Southern blot for detection, analysis and screening transgenic plants, Southern blot analysis is the most popular method for identification of transgenic DNA and also the copy number [7]. In spite of its accurate results, it is labouring and time consuming method especially during assaying many samples and can consume important portions of the genomic DNA [8].

PCR methods using transgene as allowing rapid detection of transgenic DNA, screening method is based on the amplification of the extracted DNA which is suitable to target primer sequence according their difference in length which is called amplification using complementary primers [9], this method can lead to undesirable background of unwanted and non-specific amplifications [10]. The modified technique will allow rapid analysis for large sample numbers to overcome the drawbacks of conventional methods.

\section{Materials and Methods}

\subsection{Plant Growth in Sterile Conditions Using Solid Media}

Arabidopsis should be grown in strict sterile conditions using solid media for the sake of experimental purposes such as choosing drug resistant and transformed plants, examining the phenotypes of young shoots and roots and determination homozygous lethal mutants of the plants. Liquid bleach for sterilization seed lines will be used.

The materials which will be used as containers for plant growth are sterile petri dish with $10 \mathrm{~cm}$ in diameter, magenta boxes or tubes for culture according to the sake of the experiment and autoclave for sterilization.

The reagents which used are Murashige and Skoog (MS) basal salt mixture, Sucrose, 2-(N-Morpholino) ethane sulfonic acid (MES), distilled water, Potassium Hydroxide (KOH), granulated agar.

In a beaker containing $200 \mathrm{ml}$ distilled water is added $1.075 \mathrm{~g}$ of (MS) basal salt mixture, $2.5 \mathrm{~g}$ of sucrose and $0.125 \mathrm{~g}$ of (MES) and stir well then add again distilled water until reaching final volume of $250 \mathrm{ml}, 2.5$ sucrose are used which represents $1 \%$ of the final volume $250 \mathrm{ml}$ as a nutrient for the plant to grow ra- 
pidly on the culture media but fungal and bacterial growth should be avoided using seed sterilization as liquid bleach sterilization.

Using PH meter adjust the $\mathrm{PH}$ of the solution to 5.7 using $1 \mathrm{M} \mathrm{KOH}$ and Weigh $250 \mathrm{~g}$ of granulated agar and add it per bottle but keep the bottle lid loose for the next step to avoid explosion by the pressure difference.

Autoclave the bottle for $20 \mathrm{~min}$ at $121^{\circ} \mathrm{C}$ with the stirring magnet for sterilization then Put the bottles on a stir plate with a low speed then lit agar medium to cool until can be held with bare hands and Label the bottom of Petri plates using permanent marker with identification number (N70756), name and date after that Pour enough media into 4 plates until coverage approximately the half of the plate depth and Leave the plates to cool at room temperature for about 1 hour to allow the agar solidify.

\subsection{Sterilizing of Seeds}

We will use as containers micro centrifuge tubes and reagents will be household bleach for sterilization, distilled water and Arabidopsis seeds.

Using micro centrifuge tubes sterilize the seeds by soaking them in $50 \%$ household bleach then Rinse the tubes 5 to 7 times in distilled water to remove all bleach residues.

\subsection{Planting Seeds}

We will use pipette for suction and distribution and micro pore tape.

Plant seeds at low density by adhering each individual seed to the pipette tip using suction, and release it into the plate containing agar in any location using the pipette tip for distribution and suction for getting rid of excess water then lit the water on the top of the agar drying before placing lid again onto the plate.

Using micro pore tape around the plate to avoid desiccation and at the same time to allow slight aeration and Place the plates in $4^{\circ} \mathrm{C}$ for 1 day for the sake of stratification which is breaking seed dormancy. Maybe it is not important for many lines but the lines is preferred to be germinated normally in a uniform way or synchronise in the case of putting them in a cold temperature for 1 to 5 days once then Transfer these plates to the growth environment then illuminate of $120-150 \mu \mathrm{mol} / \mathrm{m}^{2} \mathrm{sec}$ continuous light and temperature of $22^{\circ} \mathrm{C}-23^{\circ} \mathrm{C}$ for allowing suitable growth condition as a simulator to sun effect to plants.

\subsection{DNA Extraction from the Plant of Transgenic Arabidopsis Seedlings}

In this step Isolate II plant DNA Kit-bio line will be used, The used reagents are AP1 Buffer, leaves from Arabidopsis seedling, RNase A stock solution, Binding buffer (PB), Wash buffer PAW1, wash buffer PAW2 and elution buffer.

The containers and devices are water bath, $1.5 \mathrm{ml}$ Eppendorf tubes, balance, Eppendorf pestle, Isolate II filter (violet), ISOLATE II plant DNA spin column (green) and silica membrane. 
Adjust water bath to $65^{\circ} \mathrm{C}$ and put aliquot of AP1 buffer in the water bath for warming it then Take one or two leaves from Arabidopsis seedlings from different two samples A \& B and Put the leaves of each sample in a separate Eppendorf tubes and cut them into very small pieces using scalpel or Eppendorf pestle after that Place a round bottomed $1.5 \mathrm{ml}$ tube on the balance and tare it and Add plant material and weigh, repeat this process until you reach $0.1 \mathrm{~g}$ then Add 400 $\mu \mathrm{l}$ of buffer PA1 and $10 \mu \mathrm{l}$ RNase A stock solution and Disrupt the tissue using Eppendorf pestle until the buffer coloured green after that Incubate the mixture in the autoclave, invert tube 2 - 3 times for mixing during incubation then Centrifuge the lysate for $5 \mathrm{~min}$ at 11,000 rpm and then Place the violet Isolate II Filter into a clean $2 \mathrm{~m}$ Collection Tube and add the lysate into the column, put ONLY the supernatant in the violet filter tube.

Note: you can snip the last $5 \mathrm{~mm}$ off of the required number of $\mathrm{p} 1000$ filter tips to make a larger hole at the end, pipette the lysate into the spin column to take all of the liquid, or you can pour the liquid directly from your Eppendorf tube, you can also transfer some plant material.

Centrifuge the tubes for $2 \mathrm{~min}$ at $11,000 \mathrm{rpm}$ and Remove ISOLATE II filter and collect clear flow-through.

Note: in case of observing pellets in flow-through, transfer the supernatant without disturbing the pellet into a new $1.5 \mathrm{ml}$ micro centrifuge tube.

Add $450 \mu$ Binding buffer (PB) and mix well by vortexing and Put ISOLATE II plant DNA green spin column into a new $2 \mathrm{ml}$ collection tube and add $700 \mu \mathrm{l}$ of the sample then Centrifuge for $1 \mathrm{~min}$ at 11,000 rpm and discard the down flow-through after that Add $400 \mu \mathrm{l}$ wash buffer PAW1 then centrifuge for $1 \mathrm{~min}$ at 11,000 rpm and discard the flow-through again.

Add $700 \mu \mathrm{l}$ wash buffer PAW2 then centrifuge for $1 \mathrm{~min}$ at 11,000 rpm and then discard the flow-through and Add $200 \mu \mathrm{l}$ wash buffer PAW 2 and centrifuge this time for $2 \mathrm{~min}$ at $11,000 \mathrm{rpm}$ for discarding wash buffer and to complete dry silica membrane then Transfer the ISOLATE II Plant DNA Spin Column to a new $1.5 \mathrm{ml}$ micro centrifuge tube.

Add $50 \mu$ l Elution buffer PG which is previously heated in the autoclave onto the centre of the membrane. Finally centrifuge $1 \mathrm{~min}$ at 11,000 rpm.

Note: label the DNA sample and store it in the fridge.

Principle PCR protocol:

Master Mix should be done rather than pipetting each component alone into a separate tube, Calculation is held according to the equation $n+1$ where $n$ represents the number of reaction tubes, an extra tube is allowed for ensuring that master mix is sufficient for pipetting into each reaction tube, so master mix for PCR will be shown in Table 1 .

Primer set 1:

Forward: GGATCTTGAAGGAATTGAAG

Reverse: ATCGTTGCCTGCCAGTGAAAC

The thermo cycle conditions for PCR will be: $94^{\circ} \mathrm{C}$ for denaturation about $15 \mathrm{~s}$, 
Table 1. Content of tubes of primer set 1 and primer set 2 of samples, positive control, negative control and no template control.

\begin{tabular}{ccc}
\hline Template DNA & Primer set 1 & Primer set 2 \\
\hline Samples & Tubes from 1 to 4 & Tubes from 1 to 4 \\
Positive control & Tube 5 & Tube 5 \\
Negative control & Tube 6 & Tube 6 \\
No-template control & Tube 7 & Tube 7 \\
\hline
\end{tabular}

$60^{\circ} \mathrm{C}$ for annealing about 30 seconds and $72^{\circ} \mathrm{C}$ for extension about $30 \mathrm{sec}$ then final extension of $72^{\circ} \mathrm{C}$ for about 120 seconds.

Primer set 2:

Forward: TAGAAACCCCAACCCGTGAAATC

Reverse: CAATGCTGATCAATTCCACAGTT

The thermo cycle conditions for PCR will be: $94^{\circ} \mathrm{C}$ for denaturation about 15 s, $62^{\circ} \mathrm{C}$ for annealing about 30 seconds and $72^{\circ} \mathrm{C}$ for extension about $30 \mathrm{sec}$ then final extension of $72^{\circ} \mathrm{C}$ for about 120 seconds.

Prepare PCR with the 4 samples which are positive transgene sample, negative transgene sample and negative control PCR with no DNA.

Calculate the quantities of each component to get the desired concentration, prepare final master mix for each component of 8 reactions but not for DNA according to the law:

$$
C_{\text {initial }} * V_{\text {initial }}=C_{\text {final }} * V_{\text {final }} \text { then multiply to } 8
$$

where $C$ is the concentration and $V$ is the volume.

The results of calculations are shown in Table 2.

So master mix will consist of:

$100 \mu \mathrm{l}$ red mix

$4 \mu \mathrm{l}$ forward primer

$4 \mu \mathrm{l}$ reverse primer

$84 \mu \mathrm{l}$ distilled water

Prepare 10 micro tubes with

$$
\begin{array}{lllll}
\text { A1 } & \text { B1 } & \text { +ve } & -v e & N \\
\text { A2 } & \text { B2 } & \text { +ve } & -v e & N
\end{array}
$$

Put DNA sample 1 in both A1 \& A2.

Put DNA sample 2 in both B1 \& B2.

Put in each tube $24 \mu \mathrm{l}$ master mix and put them into PCR.

Gel electrophoresis protocol:

In this gel electrophoresis TBE will be prepared which is a buffer used to make the gel as shown in Table 3 so make firstly $500 \mathrm{ml}$ of TBE which is abbreviation of mixture of Tris base + boric acid + EDTA.

Use $500 \mathrm{ml}$ bottle filled with distilled water and weigh the reagents and dissolve them then mix them using stirring magnet. 
Table 2. Quantities and concentrations of tubes by micro after making master mix containing reagents of red mix, forward primer, reverse primer, template DNA and distilled water.

\begin{tabular}{ccccc}
\hline Reagents & $\begin{array}{c}\text { Initial } \\
\text { concentration }\end{array}$ & $\begin{array}{c}\text { Final } \\
\text { concentration }\end{array}$ & $\begin{array}{c}\text { Quantity }(\mu \mathrm{l}) \\
\text { for 1 reaction }\end{array}$ & $\begin{array}{c}\text { Quantity }(\mu \mathrm{l}) \\
\text { for 8 reactions } \\
\text { (master mix for } \\
\text { each primer set) }\end{array}$ \\
\hline Red mix & $2 \times$ & $1 \times$ & $12.5 \mu \mathrm{l}$ & $100 \mu \mathrm{l}$ \\
Forward primer & $10 \mu \mathrm{M}$ & $0.2 \mu \mathrm{M}$ & $0.5 \mu \mathrm{l}$ & $4 \mu \mathrm{l}$ \\
Reverse primer & $10 \mu \mathrm{M}$ & $0.2 \mu \mathrm{M}$ & $0.5 \mu \mathrm{l}$ & $4 \mu \mathrm{l}$ \\
Template DNA & - & - & $1 \mu \mathrm{l}$ & - \\
Distilled water & - & - & $10.5 \mu \mathrm{l}$ & $84 \mu \mathrm{l}$ \\
Total & - & - & $25 \mu \mathrm{l}$ & $192 \mu \mathrm{l}$ \\
\hline
\end{tabular}

Table 3. Main components and quantities of reagents used to prepare for gel electrophoresis. Tris base, boric acid, ethylene diamine tetra acetic acid (EDTA) and distilled water.

\begin{tabular}{cc}
\hline Reagent & Amount \\
\hline Tris base & $5.4 \mathrm{~g}$ \\
Boric acid & $2.75 \mathrm{~g}$ \\
EDTA & $0.292 \mathrm{~g}$ \\
Distilled water & $500 \mathrm{ml}$ \\
\hline
\end{tabular}

Weigh $2 \mathrm{~g}$ agarose and pour from TBE solution until reaching $100 \mathrm{ml}$ then dissolve it by using the microwave until solution becomes clear and homogenous then put SYBR safe DNA stain about $10 \mu$ l.

Pour the gel in the cast without removing combs and leave it to solidify.

After solidification pour some TBE and remove combs gently then pipette 10 $\mu \mathrm{l}$ of each well as Table 4.

Southern blot protocol:

Connect the cast to the power (black wire is negative and red is positive) and make electric current running at $110 \mathrm{~V}$ for about $20 \mathrm{~min}$ and put the cast into the southern blot.

\section{Results}

\subsection{Plant Seeding}

After treating seeds with $1 \%$ sucrose, small shoots have been grown within 6 days as shown in Figure 1.

\subsection{Identification of Transgenic Arabidopsis}

The southern blot analysis was performed after PCR and showed no data of transgenic DNA for the lines of Arabidopsis. 


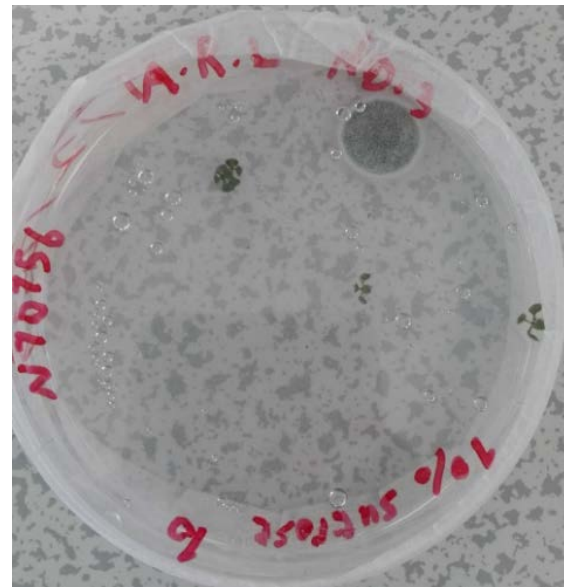

Figure 1. Shoots of Arabidopsis N70756 grown by using 1\% sucrose after bleaching the seeds for sterilization.
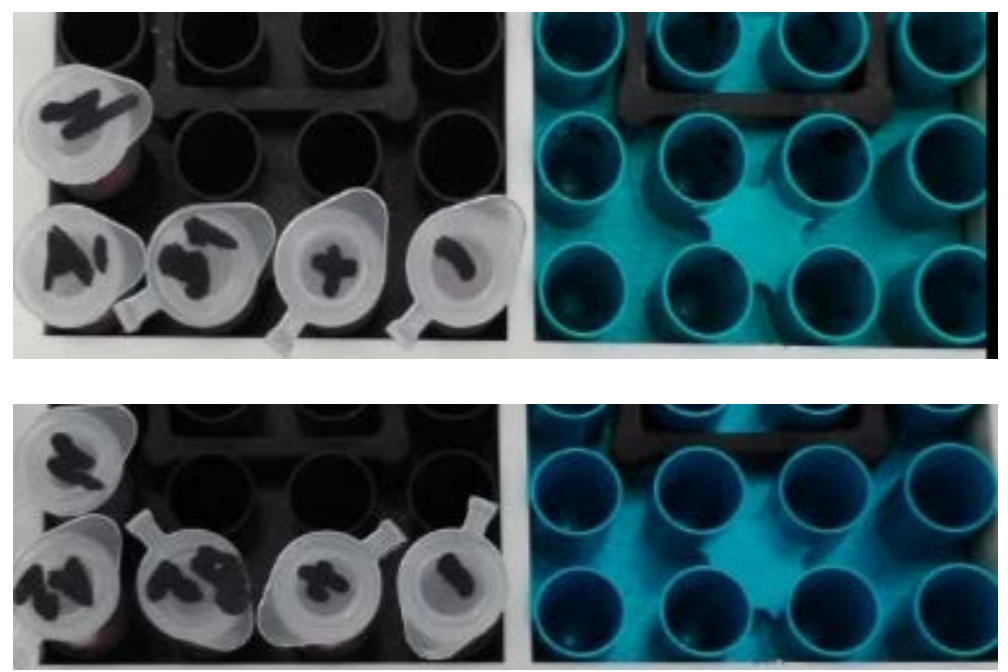

Figure 2. Samples loaded on PCR; the upper tubes N: No template control, A1: DNA of sample A Arabidopsis, (B1): DNA of sample B Arabidopsis, (+): positive control; (-): negative control; the lower tubes N: No template control; A2: DNA of sample A Arabidopsis, B2: DNA of sample B Arabidopsis, (+): positive control; (-): negative control.

Table 4. Scheme of wells which will be filled to be used in Southern blot analysis, sample A1, sample B1, positive control, negative control, no template, sample A2, sample B2, positive control, negative control, no template and ladder.

\begin{tabular}{ccccccccccccccccc}
\hline Well & 1 & 2 & 3 & 4 & 5 & 6 & 7 & 8 & 9 & 10 & 11 & 12 & 13 & 14 & 15 & 16 \\
\hline Content & A1 & B1 & +ve & - ve & NT & & A2 & B2 & +ve & - ve & NT & & & & & Ladder \\
\hline
\end{tabular}

\subsection{Southern Blot Analysis of Transgenic Arabidopsis}

Several levels of transgenic or not transgenic Arabidopsis cell lines were analyzed using southern blot, the results as Figure $2 \&$ Figure 3 show no transgenic cell lines except for ladder which may indicate error in pipetting or predict that both DNA samples A \& B are not transgenic [11] as DNA may be not extracted in both samples. 


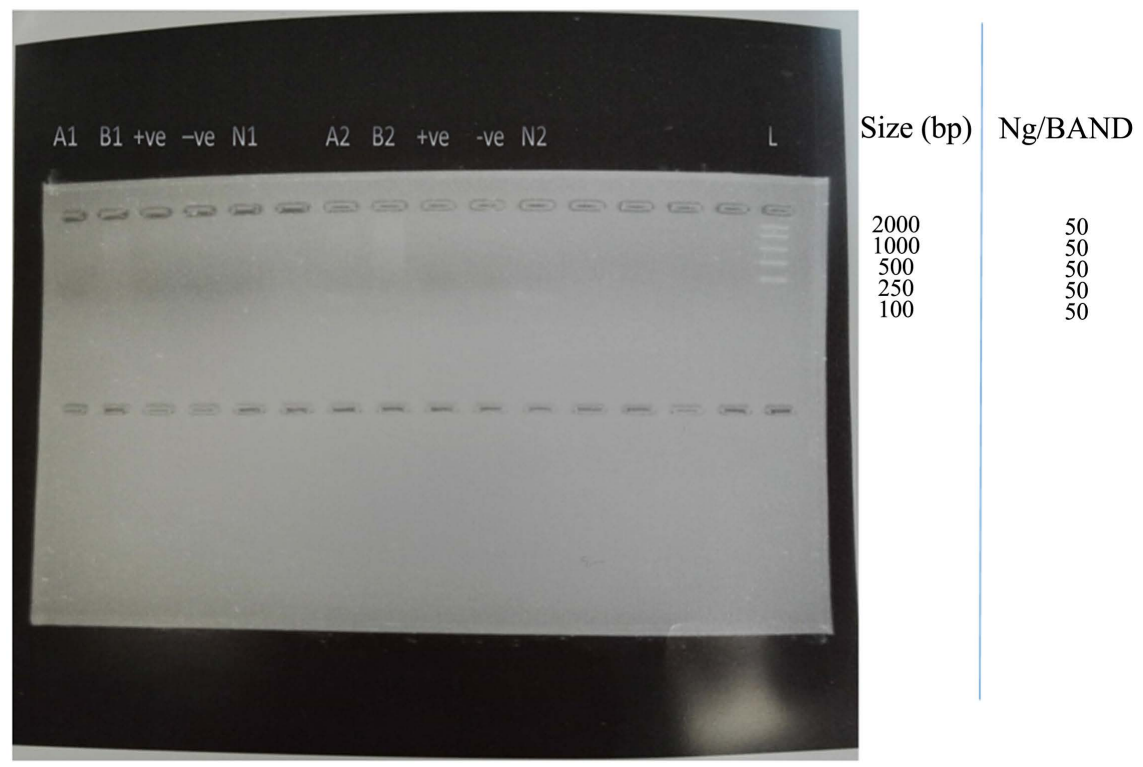

Figure 3. Amplification products from PCR and Southern blot analysis obtained from transgenic A and B DNA samples after Gel electrophoresis of the PCR amplification products. Lane 1 (A1): DNA of sample A Arabidopsis, lane 2 (B1): DNA of sample B Arabidopsis, lane 3 (+ve): positive control; lane 4 (-ve): negative control; lane 5 (N1): No template control; lane7 (A2): DNA of sample A Arabidopsis; lane 8 (B2): DNA of sample B Arabidopsis; lane 9 (+ve): positive control; lane 10 (-ve): negative control; lane 10 (N2): No template control; lane $16(\mathrm{~L})$ : molecular marker $1 \mathrm{~kb}$ plus DNA Ladder (Life Technologies).

Positive and negative controls show low expression of the gene.

\section{Discussion}

According to protocol, there are 2 given primer sets which are DNA sequences for targeting Arabidopsis, each primer set consists of forward strand and reverse strand, primer set 1 sequence is:

\section{Forward: GGATCTTGAAGGAATTGAAG}

Revers: ATCGTTGCCTGCCAGTGAAAC

And primer set 2 sequence is:

\section{Forward: TAGAAACCCCAACCCGTGAAATC \\ Reverse: CAATGCTGATCAATTCCACAGTT}

By using The Basic Local Alignment Search Tool (BLAST) to find similarity between these primers to compare nucleotide sequences databases and adjust them on Arabidopsis taxid, the target sequence found in primer set 1 is for determining DNA extraction, it is similar to Arabidopsis thaliana ubiquitin-conjugating enzyme 10 (UBC10), mRNA which its sequence is

GTTAAAAGTAGAGTCCACTAGTCAAAGAAAGTAAATAATCCACACG GTATTTATTGTAGACGTGAGCACA

GAGAATAATTCGTATTCTTCGTCTTTCGTCCACCACCATCTCTATTTT CTTCCTTTCCCCTAAGTCTTGG

TTCTTCTTCTCTCTAATACGAGAAGAAAAAGGCGAAAACCTCGCCAA 


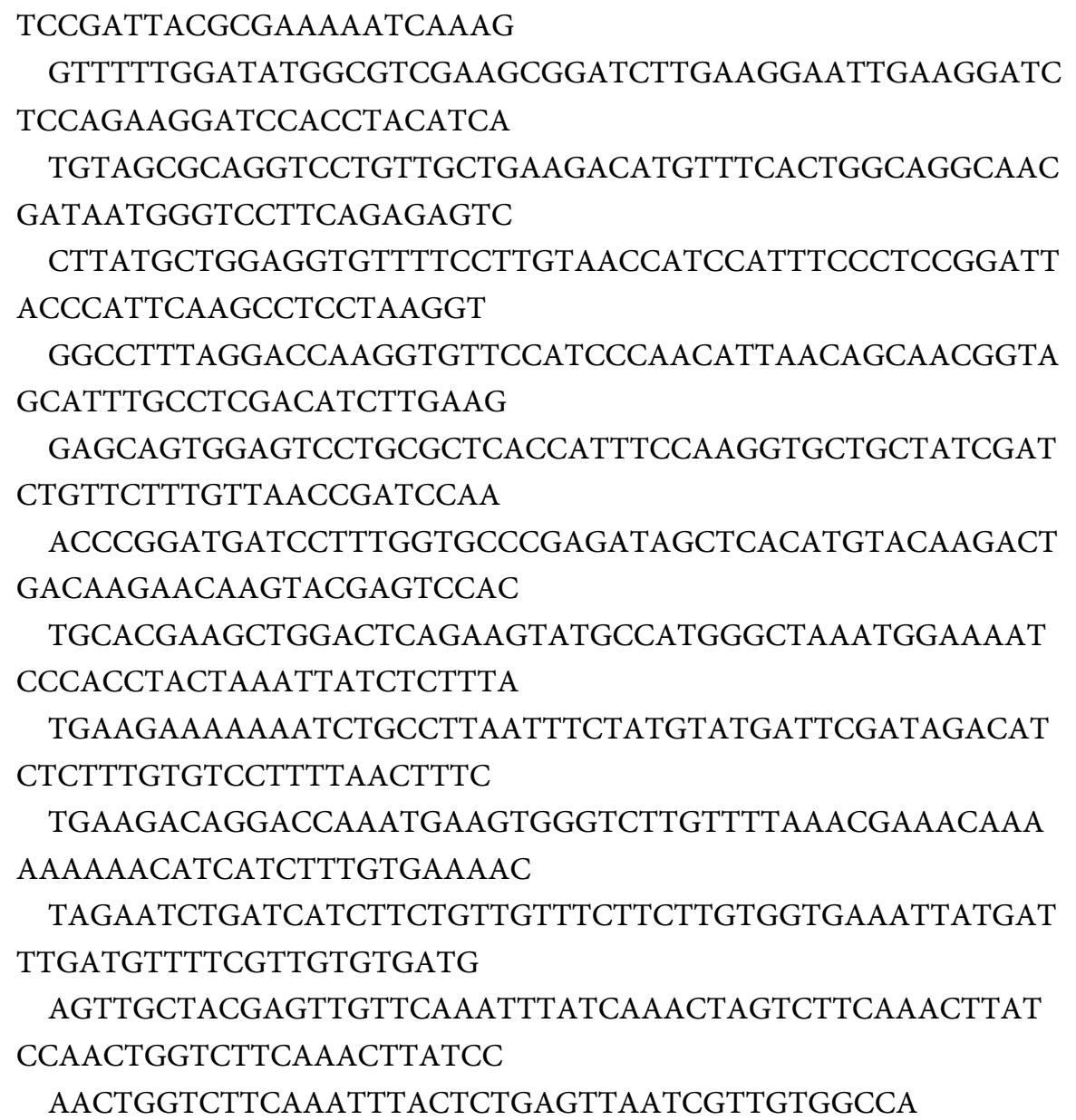

This target sequence has been chosen because it is similar for the sequence of primer set 1 which has identity by $100 \%$.

The target sequence found in primer set 2 is for determining DNA transgenicity, it is similar to Arabidopsis thaliana transgenic line M57 T-DNA tagged transcription start site, partial sequence and beta glucuronidase mRNA, partial cds which its sequence is

CACACGATTTATTAAACGCTGCACTTGGCTAGAACTAGTGGATCCCC GGGTAGGTCAGTCCCTTATGTTA CGTCCTGTAGAAACCCCAACCCGTGAAATCAAAAAACTCGACGGCC TGTGGGCATTCAGTCTGGATCGCG AAAACTGTGGAATTGGTCAGCGTTGGTGGGAAAGCGCGTTACAAGA AAGCCGGGCAATTGCTGTGCCAGG CAGTTTTAACGATCAGTTCGCCGATGCAGATATTCGTAATTATGCGG GCAACGTCTGGTATCAGCGCGAA GTCTTTATACCGAAAGGTTGGGCAGGCCAGCGTATCGTGCTGCGTTT CGATGCGGTCA

This target sequence has also been chosen because it is similar for the sequence of primer set 2 with $100 \%$ identity.

So primer set 2 will be used for identification of transgenic lines of Arabidopsis, generally there are many other assay methods which can be used to check the 
presence of the reporter gene in the transgenic lines like fluoremetric assay and histochemical assay [12].

Another method which is very specific for plants is GUS assay which depends mainly on using $\beta$-glucuronidase enzyme, it is perfect method for detection of single cells through staining them blue without using any complicated techniques, and the main disadvantage of this method is that cells are killed in this method but however this method is very popular in plant science [13].

Although plant seeding was very successful due to using $1 \%$ sucrose but Southern blot did not show any results may be due to error in pipetting or because results are negative due to absence of transgenic DNA in both samples or DNA degradation.

Another possibility may be because DNA is not extracted as the results show low expression of the gene.

\section{Conclusions}

In summary, the transgenic Arabidopsis species overexpression can be detected using PCR and Southern blot analysis for detection the transgenic DNA and using the primers which are target sequence of the DNA to determine the suitable cell lines, although PCR is suitable for quantification DNA especially with plants containing high copy numbers.

In these experiments, transgenic plants contain more than one copy of transgene according to Southern blot analysis, so further experiments can be done in the future to detect the transgene related to the copy number so according to the results there is no match between using PCR and southern blot analysis.

The results demonstrate that the required detection of transgenic Arabidopsis are not fulfilled maybe because of problems in pipetting or due to contaminations which contribute and interfere with results, this interference is too low to determine that the samples are not transgenic and using the sets of primers will be helpful for this assay using BLAST server so the determination will be possible if the PCR effect is lower [14].

DNA may not be extracted well and the expression of the gene is very low.

Contamination and interference is not easy to be avoided especially during using Agrobacterium based procedures for transformation of Arabidopsis to be reproducible to deliver correct results with contaminated plants, in the labs which use Agrobacterium procedures for transformation of Arabidopsis, Southern blot analysis technique is the method of choice for transgene determination [15].

Further research can be done in the future using very specific methods like GUS, histochemical assay which depends on the tissue culture of the plant and also fluorimetric assay which can be considered as a marker for transgenic gene.

\section{Conflicts of Interest}

The authors declare no conflicts of interest regarding the publication of this paper. 


\section{References}

[1] First Species of Plant to Flower in Space. Guinness World Records.

[2] Leuzinger, K., Dent, M., Hurtado, J., Stahnke, J., Lai, H., Zhou, X. and Chen, Q. (2013) Efficient Agroinfiltration of Plants for High-Level Transient Expression of Recombinant Proteins. Journal of Visualized Experiments, 77, e50521. https://doi.org/10.3791/50521

[3] Schell, J. and Van Montagu, M. (1977) The Ti-Plasmid of Agrobacterium tumefaciens, a Natural Vector for the Introduction of NIF Genes in Plants? In: Hollaender, A., Burris, R.H., Day, P.R., Hardy, R.W., Helinski, D.R., Lamborg, M.R., Owens, L. and Valentine, R.C., Eds., Genetic Engineering for Nitrogen Fixation. Basic Life Sciences, Springer, Boston, 159-179. https://doi.org/10.1007/978-1-4684-0880-5 12

[4] Joos, H., Timmerman, B., Montagu, M.V. and Schell, J. (1983) Genetic Analysis of Transfer and Stabilization of Agrobacterium DNA in Plant Cells. The EMBO Journal, 2, 2151-2160. https://doi.org/10.1002/j.1460-2075.1983.tb01716.x

[5] Thomson, J.A. (2016) Genetic Engineering of Plants. Biotechnology, 3, 7 p.

[6] Arnold, C. and Hodgson, I.J. (1991) Vectorette PCR: A Novel Approach to Genomic Walking. Genome Research, 1, 39-42. https://doi.org/10.1101/gr.1.1.39

[7] Hobbs, S.L., Warkentin, T.D. and DeLong, C.M. (1993) Transgene Copy Number Can Be Positively or Negatively Associated with Transgene Expression. Plant Molecular Biology, 21, 17-26. https://doi.org/10.1007/BF00039614

[8] Iglesias, V.A., Moscone, E.A., Papp, I., Neuhuber, F., Michalowski, S., Phelan, T., Spiker, S., Matzke, M. and Matzke, A.J. (1997) Molecular and Cytogenetic Analyses of Stably and Unstably Expressed Transgene Loci in Tobacco. The Plant Cell, 9, 1251-1264. https://doi.org/10.1105/tpc.9.8.1251

[9] Siebert, P.D., Chenchik, A., Kellogg, D.E., Lukyanov, K.A. and Lukyanov, S.A. (1995) An Improved PCR Method for Walking in Uncloned Genomic DNA. Nucleic Acids Research, 23, 1087-1088. https://doi.org/10.1093/nar/23.6.1087

[10] McGarvey, P. and Kaper, J.M. (1991) A Simple and Rapid Method for Screening Transgenic Plants Using the PCR. BioTechniques, 11, 428-432.

[11] Kliebenstein, D.J., Monde, R.A. and Last, R.L. (1998) Superoxide Dismutase in Arabidopsis: An Eclectic Enzyme Family with Disparate Regulation and Protein Localization. Plant Physiology, 118, 637-650. https://doi.org/10.1104/pp.118.2.637

[12] Nguyen, V.T., Morange, M. and Bensaude, O. (1988) Firefly Luciferase Luminescence Assays Using Scintillation Counters for Quantitation in Transfected Mammalian Cells. Analytical Biochemistry, 171, 404-408.

[13] Nolan, G.P., Fiering, S., Nicolas, J.F. and Herzenberg, L.A. (1988) Fluorescence-Activated Cell Analysis and Sorting of Viable Mammalian Cells Based on Beta-D-Galactosidase Activity after Transduction of Escherichia coli lacZ. Proceedings of the National Academy of Sciences of the United States of America, 85, 2603-2607.

[14] Ingham, D.J., Beer, S., Money, S. and Hansen, G. (2001) Quantitative Real-Time PCR Assay for Determining Transgene Copy Number in Transformed Plants. BioTechniques, 31, 132-140. https://doi.org/10.2144/01311rr04

[15] Mason, G., Provero, P., Varia, A.M. and Acotto, G.P. (2003) Estimating the Number of Integrations in Transformed Plants by Quantitative Real-Time PCR. BMC Biotechnology, 2, Article No. 20. 